\title{
Adaptive Approach of DSR and OLSR Routing Protocols Using Optimal Probabilistic Logical Key Hierarchy in MANET
}

\author{
Harshit Prakash Patidar and Neetu Sharma
}

\begin{abstract}
Wireless network with ad-hoc behaviour consists of mobile nodes which facilitates a fundamental architecture for communication without any support of traditional, steady and fixed-positioned routers. However, the architecture must preserve communicating routes and hosts have mobile nature and their restricted transmission range. There are several protocols for managing the routing in the mobility atmosphere. In the MANET, the mobile nodes can perform the roles of both hosts and routers. Various MANET applications are used for Military strategic communications and Disaster recovery mostly depend on secure node communication. For Secure Communication, we use several Logical Hierarchy Key protocols in Mobile Ad-hoc Network but the group key administration looks upon many problems assuming due to unreliable media, mobile node failure and less energy resources. In this paper, we analyze new logical key with Optimal Probabilistic Technique in DSR and OLSR routing protocols in Mobile Ad-hoc Network. In this key, all nodes are shaped in a tree structure. OPLKH decreases the Rekey Cost and several routing energy consumptions in Mobile Ad-hoc Network. In simulation, we calculate the amount of Rekeys Cost, Energy Consumption for Data Transmission, Energy Consumption for Routing and Energy Consumption for Key Generation in the network.
\end{abstract}

Keywords--- Automatic-Configuring Infrastructure, Energy Consumption, Rekey Cost.

\section{INTRODUCTION}

$\mathrm{W}$ IRELESS communication technology is not practical with a particular architecture for all wireless networks because of fixed behaviour of wireless nodes or devices. Wireless communication technology is growing at high speed. Wireless networks with mobile nodes such as ad-hoc wireless networks must have functionality to be self-organized and self-configured because of the mobile nature of devices and networks.

On these networks, mobile devices or hosts have a limited transmission range to communicate with other hosts. If a host wants to send data to another host which is not within the transmission range of the source node, then the data must be

Harshit Prakash Patidar, Department of Computer Science, Govt. Engg. College, Ajmer, Rajasthan. E-mail:harshitprakash@gmail.com

Neetu Sharma, Department of Computer Science, Govt. Engg. College, Ajmer, Rajasthan. E-mail:neetucom10@gmail.com

DOI: 10.9756/ BIJNTA.8131 expressed through the network using other nodes which can play the role of routers in delivering the message all over the network. Broadcasting must be used for sending messages by the mobile hosts and host nodes should be in tremendously activate mode for accepting any message that it has received. Hosts can be single directional that can transmit only in one direction at a time in the ad-hoc network so that the communication is not bidirectional as usually in wireless communication systems. [1]

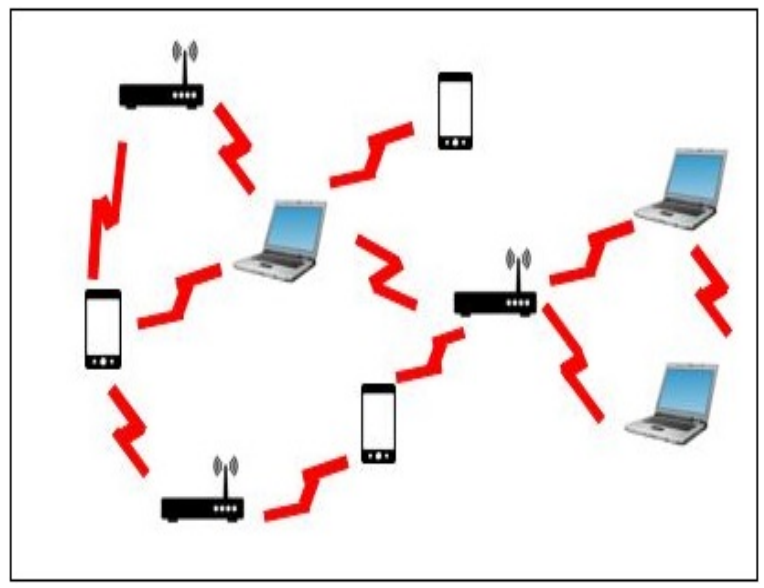

Figure 1: Infrastructure Less Network

Routing Protocols should have the capability of handling many numbers of hosts with their limiting energy resources and limiting bandwidths in Wireless Ad-hoc Networks. Host mobility is the main challenge for routing protocols. By the management of mobility systems, hosts can appear and disappear at various locations in the network. Although in adhoc networks, all hosts in the network perform their role as routers and must have participated in route maintenance and route discovery for other nodes or hosts in the network. It is also essential for ad-hoc routing protocols to reduce routing message overhead, growing mobility and number of hosts. Routing tables must be kept smaller because increasing the routing table size will interrupt control packets of host sent on the network and will eventually increase the large link overhead. [1] [2]

\section{OVERVIEW OF OLSR AND DSR ROUTING PROTOCOLS}

Routing protocols find the shortest path from source to destination and are categorized into two categories based on time taken for route discovery and when to discover the routes. One of the main routing protocols of Proactive Routing Protocol is OLSR. It's one of the major functionalities is to 
maintain recent reflecting routing information by sending control messages, recurring at regular intervals between the hosts which updates their routing tables. All the updates are forwarded all over the network if any changes are found in the structure. Link state routing algorithms are used by the Proactive Routing Protocols to flood frequently the link information about its adjacent nodes. On-demand routing protocols are other routing protocols in which it generates routes when they have exigency of the source hosts and route maintenance as it is required. Such protocols use distance vector routing algorithms. These protocols have vectors that contain selective information about the path to the destination and the cost. Whenever nodes interchange vectors of their information, each host transforms possessed routing information when they have a requirement.

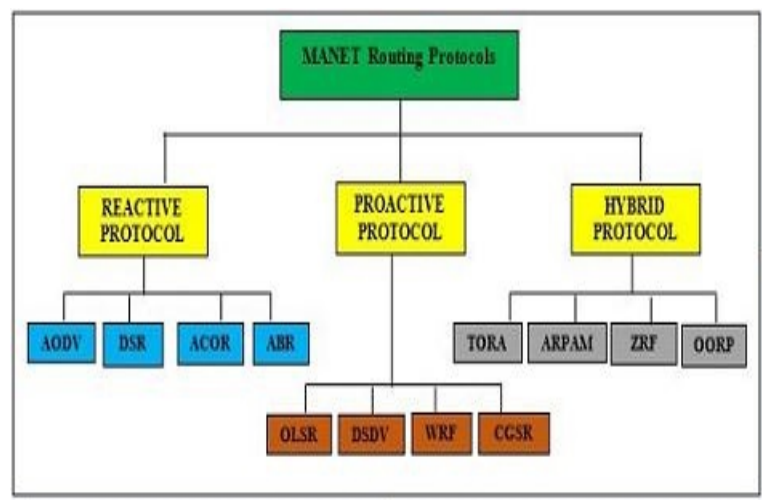

Figure 2: Classification of Routing Protocols

\subsection{Proactive (Table-Driven) Routing Protocols}

Proactive Routing Protocols are table driven routing protocols to broadcast the data packets, every node has its routing table and every node needs to step up connections to some other existing hosts of the networks. All the nodes of the network maintain their records related to all existing destinations, required number of hops mandatory to get in at every recorded destination in the tabular form. All the entries in the routing table are labeled with a particular sequence number that are produced by the destination nodes. For the stability retaining, every source node broadcasts and transforms its table of routing regularly. On the basis of routing tables, how many numbers of hops are required to reach from a specific source node to a destination node are calculated and which stations are receptacle is measured by the broadcasting of packets among the nodes. Every broadcasting data node contains a new number with sequence and for every new route node, maintains the information as given below. [5]

- Number of hops obligatory to reach a specific destination node.

- New sequence number for every destination and Contains destination address.

Basically, table driven routing protocols are more beneficial for the networks that contain the least number of hosts in the network because all the hosts need to inform their node entries to all other hosts on the network. There is additional bandwidth Consumption in the routing table and the higher routing overhead problem is classified. [6]
- Optimal Link State Routing Protocol is the example of Proactive Routing Protocol.

\section{Optimal Link State Routing Protocol (OLSR)}

Proactive routing protocol interchanges routing statics with other hosts in the network. Multi Point Relays (MPRs) are the key idea used in OLSR. MPR is used to decrease the number of control packets required for the data transmission. To forward traffic of data in the network, a host picks its single hop symmetric neighbors termed as MPRs set that protects all hosts that are two hop away. MPR hosts or nodes have responsibility for forwarding control traffic in OLSR while in the classical link state algorithm, all the nodes forward the messages. Battery consumptions can be reduced in OLSR using other existing link state algorithm. [7] [8]

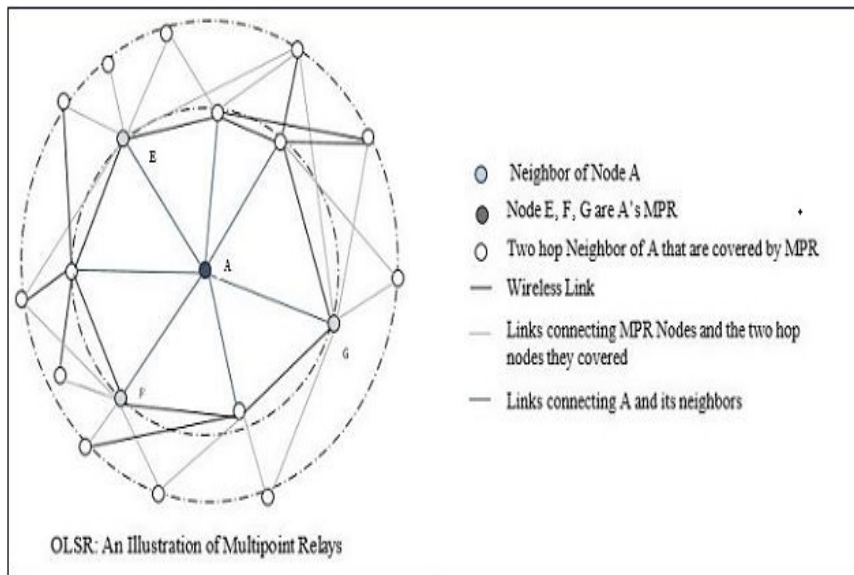

Figure 3: OLSR Routing Protocol

\subsection{Reactive (On-Demand) Routing Protocol}

On-demand routing protocols determine routes on-demand that is the reason of the reactive routing protocol has less overhead problems as compared to proactive routing protocols. This type of protocols uses global searching (flooding) conception. In on-demand technique, consistent updates in routing tables with newer rout topology is not desired. In on-demand routing protocols, it looks for the routing in proactive method and create the link. In order to send and accept the packets from a source host or node to a destination node, the route discovery method is applied by the flooding or oversupplying the RREQ (route request) packets all over the network. [9]

- $\quad$ DSR and AODV are the example of Reactive Routing Protocol.

\section{Dynamic Source Routing Protocol (DSR)}

DSR is one of the on-demand routing protocols when a source node floods packets; the transmitter node hives up hopby-hop route to the recipient node. It applies source routing concept. The list of routes is cached in a source cache. Source routes are kept in the packet header by the data packets. Dynamic source routing follows the route discovery method to send the data packets from sender node to the receiver node for which it does not intimate discovery process to actively accretion such a route. In route discovery, DSR works by spreading the data packets in network with RREQ (route request) packets. In DSR protocol, Periodic hello message 
transmission is not required. Dynamic Source Routing (DSR) is beaconless on-demand routing protocol.

RREQ packets are found by all closer nodes and continue the flood spreading process by retransmission of RREQ packets unless it acquires destination host or its route cache consists of a route for the destination node, such as a host responds to the RREQ with a RREP (route reply) packet that is routed back to the actual source node. Source routing applies route request RREQ and route reply RREP packets. The RREQ establishes the path traversed all over the network. The route reply (RREP) packets, routes themselves back to the source by traversing this path towards the back. The source hives up backward route by RREP packets for forthcoming use. If any connection on a source route is intoxicated, a route error (RERR) packet is apprised to the source host. [9]

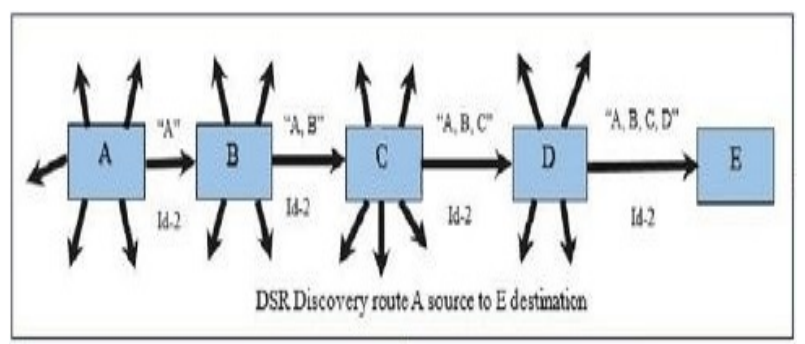

Figure 4: DSR Routing Protocol

\section{Description OF Mobility Model}

In mobility model, the Random Waypoint Mobility Model is a random model for the movement of mobile nodes explaining how their location, velocity and acceleration changes over the time. Mobility models are used for simulation purposes when any new network protocols are estimated. The random waypoint mobility model was first proposed by Maltz and Johnson. It is one of the most popular mobility models to calculate Mobile Ad-hoc Network (MANET) routing protocols because of its simplicity and wide availability.

In random-based mobility simulation models, the mobile nodes move randomly and independently without any restrictions. To be more specific, the destination, speed and the way are all chosen randomly and independently of the other nodes. This type of model has been used in many simulation projects.

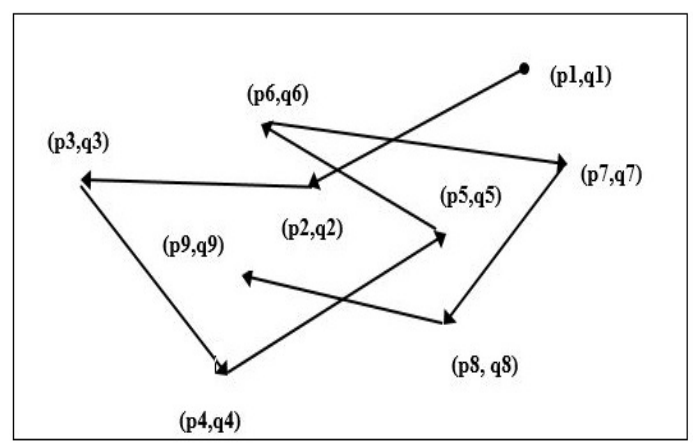

Figure 5: Random Waypoint Mobility Model

The Random Walk Mobility Model and the Random Direction Mobility Model are two different kinds of variants of the Random Waypoint Mobility Model. [10]

\section{ENERGy CONSUMPTION MODEL}

We have calculated the energy consumption for data transmission and receiving as proposed by Dongkyun Kim (Dongkyun Kim. Et al. 2002) and for key generation proposed by Potlapally Nachiketh (Nachiketh R. et al. 2003)

The energy consumption required to transmit a packet $p$ then the energy $\mathbf{E}(\mathbf{p})=\mathbf{i}^{*} \mathbf{v}^{*} \mathbf{t}_{\mathbf{p}}$ Joules where $\mathbf{i}$ is new value, $\mathbf{v}$ is the voltage and $\mathbf{t}_{\mathrm{p}}$ is the time occupied to transmit the packet p. Energy consumption for the key setup phase using AES of 128-bit key is $7.83 \mathrm{uJ} / \mathrm{key}$. We use symmetric key of AES of 128-bit length for simulation. [11]

\section{OUR APPROACH}

We analyze OPLKH methods which are basically used for the optimization for PLKH resulting reduced the Rekey cost more. We also establish the LKH tree structure regarding the member Rekey Probabilities as opposed to the cumulative probability of PLKH. We emphasis on the decreasing of number of Rekeys that are caused due to member compromise or eviction. [12]

In the tree structure, members are as leaf nodes which are same as in PLKH. We assemble it for a new insert operation which places the members either as a leaf node or as an internal node in the LKH tree structure which is based on their probabilities. When any new member $\mathrm{C}$ joins the group, member $\mathrm{C}$ is placed at a position such that all the ancestors of $\mathrm{C}$ will have higher probability and all the descendants of $\mathrm{C}$ will have lesser probability. [12] [13]

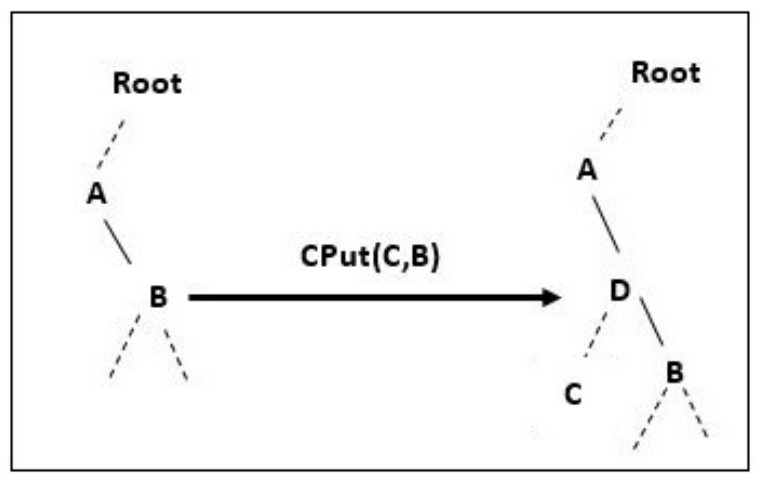

Figure 6: CPUT Operation

The LKH scheme aims to reduce the cost of a negotiation recovery process by adding extra encryption keys into the system. The members of the group are organized as the leaves of a "logical" key tree structure preserved by the key manager. The internal nodes in this tree structure are rational entities which do not relate to any real life entities of the multicast group but are used for key distribution purpose only. There is a key linked with each node in the tree structure and each member holds a replica of every key on the path from its corresponding leaf node to the root node of the tree structure. [14] [15].

When a fellow node leaves the group, its related corresponding physical node is required to be removed from 
the tree structure. The physical node may be an internal node or an external node based on how it is injected and whether it has any dependent nodes at present. In OPLKH scheme, physical node is removed by delete procedure only if it is a leaf node otherwise delete operation sets its type as consumable and refresh affected keys. [14] [15]

With the development of the centralized key management, the tree structure key scheme is improved and the cost of Rekeying from Probability 0 (m) to 0 (log $\mathrm{m}$ ) is reduced where $\mathrm{m}$ denotes the group size. MANET accepted the OPLKH method and analyzed the Rekey Cost and energy consumption for key generation, data transmission and routing in the network. [17] [18]

\section{Proposed Methodology for the Manet}

In this method, we have concentrated on reducing the cost of Rekey of LKH based protocols by organizing the tree structure based on Rekey Probabilities of nodes.

In OPLKH scheme, we have implemented all the logical actions of OPLKH into MANET atmosphere. In MANET, we have chosen clusterhead as a key-server because there is no key-server. Weighted clustering algorithm (WCA) is used for selecting clusterhead. As Rekey Probability is one of the major things to cause Re-clustering, we have considered Rekey Probability to be another factor in Weighted Clustering Algorithm. [16]

The WCA has the softness of taking combined effect of the degree and assigning different weights of ideality, node mobility, battery power and transmission power. The updated WCA algorithm as follows:

\section{Clusterhead Selection Technique}

Step 1: Find the neighbours of each node $\mathbf{v}$ (i.e. nodes within its broadcast range). This gives the degree, $\mathbf{d}_{v}$, of this node. $\mathbf{H}$ is number of nodes, a clusterhead can handle.

Step 2: Calculate the degree-difference, $\mathbf{D}_{v}=\left|\mathbf{d}_{\mathbf{v}}-\mathbf{H}\right|$, for every node $\mathbf{v}$.

Step 3: For every node, compute the sum of the distances, $\mathbf{S}_{\mathrm{v}}$, with all its neighbours.

Step 4: Calculate the running average of the speed for every node $\mathbf{v}$. This provides the mobility of the node $\mathbf{v}$ and is denoted by $\mathbf{M}_{\mathbf{v}}$.

Step 5: Calculate the consumed battery power, $\mathbf{T}_{\mathbf{v}}$. Since we assume that consumption of battery power is more for a clusterhead than for an ordinary node.

Step 6: Calculate a combined weight $\mathbf{I}_{\mathbf{v}}=\mathbf{c}_{\mathbf{1}} * \mathbf{D}_{\mathbf{v}}+\mathbf{c}_{\mathbf{2}} * \mathbf{S}_{\mathbf{v}}$ $+\mathbf{c}_{3} * \mathbf{M}_{\mathbf{v}}+\mathbf{c}_{4} * \mathbf{T}_{\mathbf{v}}$, for each node $\mathbf{v}$.

The coefficients $\mathbf{c}_{\mathbf{1}}, \mathbf{c}_{\mathbf{2}}, \mathbf{c}_{\mathbf{3}}$ and $\mathbf{c}_{\mathbf{4}}$ are the weighting factors for the corresponding system parameters.

Step 7: Calculate the average weights of all nodes, AI, and also compute the average Rekey Probabilities of all nodes, ARP.

Step 8: Now check for each node $\mathbf{v}$.

If (weight $\mathbf{I}_{\mathbf{v}}<\mathbf{A I}$ and corresponding Rekey Probability,
$\left.\mathbf{R P}_{\mathbf{v}}<\mathrm{ARP}\right)$.

Then Calculate the new weight $\mathbf{N I}_{\mathbf{v}}=\mathbf{I}_{\mathbf{v}} * 0.001+\mathbf{R P}_{\mathbf{v}}$.

Step 9: Choose the node with minimum $\mathbf{N I}_{\mathrm{v}}$ to be the cluster head. (Key-server).

By using the improved WCA algorithm, primarily we choose the best node as clusterhead from the existing nodes to escape Re-clustering. The following key features are considered in this Weighted Clustering Algorithm-

a) The clusterhead selection method is a periodic and is invoked as barely as possible. It reduces system updates and reduces computational and communicational costs.

b) To confirm efficient MAC functioning, each clusterhead can ideally support a pre-defined system threshold node. By optimizing or limiting the number of nodes in each cluster, the systems high throughput can be achieved.

c) The battery power can be skillfully used within certain transmission range. If a node works as a clusterhead rather than an ordinary node, consumption of the battery power is extra. [16]

\section{Simulation Result and ANalysis}

Optimal Probabilistic Logical Key is simulated in Mobile Ad-hoc Network. C++ language is used for simulation. Groups of 128, 256, 512, 768 and 1024 nodes are experiments for implementing. For each experiment, we have produced the joining/leaving of nodes arbitrarily, in addition, some members may leave because of power exhaustion and some members may join/leave based on connection failure or availability. For each join/leave operation, we have documented the numbers of Rekeys generated and energy consumption for key generation.

In OPLKH method, we have categorized three categories namely static, semi-dynamic and dynamic based on number of leaves and Rekey Probabilities. But in MANET, we added some extra parameters to classify these categories. The additional parameters are pause time, node mobility and updating interval time. The additional parameters are listed in Table 1 . In simulation, for every updating interval time, we have updated the node positions and routing tables.

Table 1: Simulation Parameter

\begin{tabular}{|l|l|l|l|}
\hline \multicolumn{1}{|c|}{$\begin{array}{c}\text { Simulation } \\
\text { Parameters }\end{array}$} & \multicolumn{1}{|c|}{ Static } & \multicolumn{1}{c|}{$\begin{array}{c}\text { Semi- } \\
\text { Dynamic }\end{array}$} & \multicolumn{1}{c|}{ Dynamic } \\
\hline Mobility & $0-5 \mathrm{~m} / \mathrm{s}$ & $0-10 \mathrm{~m} / \mathrm{s}$ & $0-20 \mathrm{~m} / \mathrm{s}$ \\
\hline Packet Size & 256 bytes & 256 bytes & 256 bytes \\
\hline Mobility Model & $\begin{array}{l}\text { Random } \\
\text { Waypoint }\end{array}$ & $\begin{array}{l}\text { Random } \\
\text { Waypoint }\end{array}$ & $\begin{array}{l}\text { Random } \\
\text { Waypoint }\end{array}$ \\
\hline Pause Time & $0-10 \mathrm{~s}$ & $0-5 \mathrm{~s}$ & $0 \mathrm{~s}$ \\
\hline $\begin{array}{l}\text { Updating } \\
\text { Interval Time }\end{array}$ & $10 \mathrm{~s}$ & $5 \mathrm{~s}$ & $1 \mathrm{~s}$ \\
\hline No. of Leaves & $\begin{array}{l}1 / 4 \text { of Group } \\
\text { Size }\end{array}$ & $\begin{array}{l}1 / 2 \text { of Group } \\
\text { Size }\end{array}$ & $\begin{array}{l}3 / 4 \text { of Group } \\
\text { Size }\end{array}$ \\
\hline Area (in sq. m) & $800 x 800$ & $800 x 800$ & $800 x 800$ \\
\hline Energy & $0-1000 \mathrm{~J}$ & $0-1000 \mathrm{~J}$ & $0-1000 \mathrm{~J}$ \\
\hline
\end{tabular}




\section{Simulation Results}

In simulation results, we have calculated the numbers of Rekeys and energy consumption for routing, data transmission and key generation in static, semi-dynamic and dynamic scenarios for each group size of 128, 256, 512, 768 and 1024 nodes.

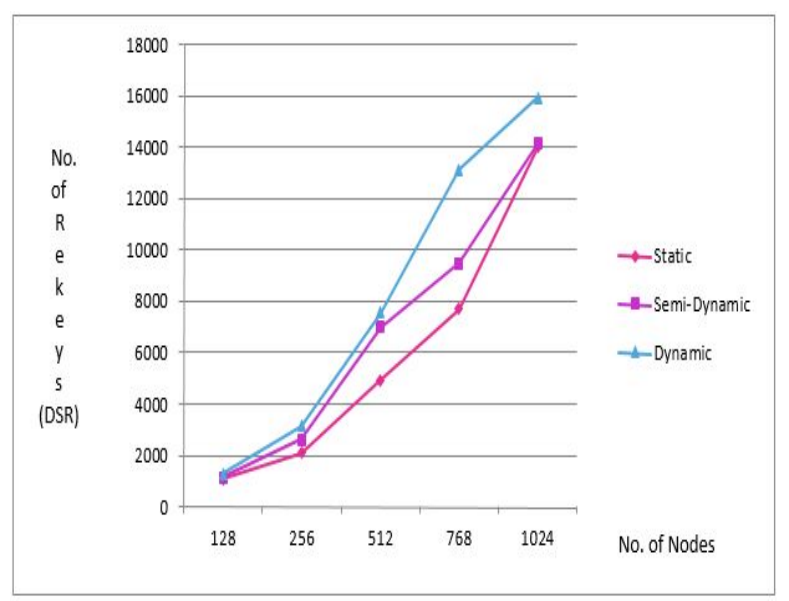

Figure 7: Graph between Number of Nodes and Number of Rekeys in case of DSR

Figure 7 shows Number of Nodes versus Number of Rekeys in the network in the case of Dynamic Source Routing Protocol. In DSR protocol, Rekey operation i.e. number of joining/leaving in the Static categories is less as compared to the Semi-Dynamic categories and Dynamic categories. Similarly, Rekey operation i.e. number of joining/leaving in the Semi-Dynamic categories is less as compared to the Dynamic categories.

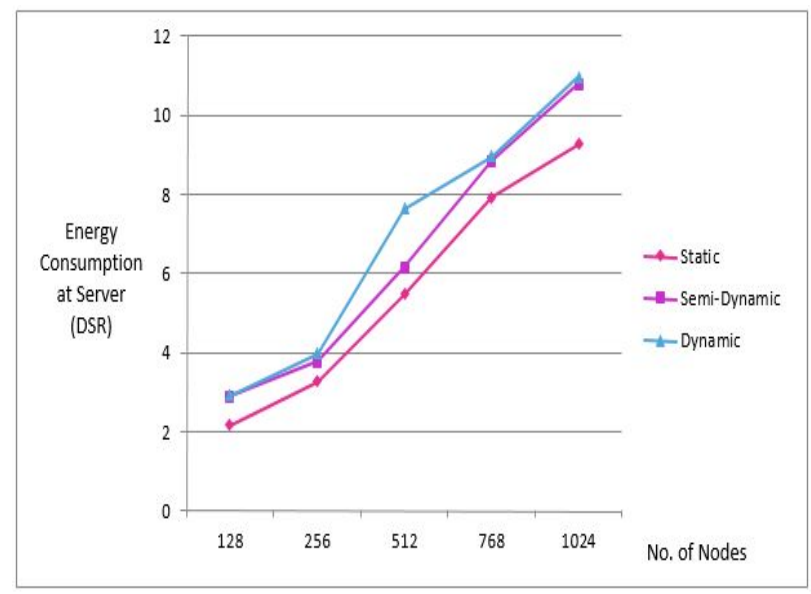

Figure 8: Graph between Number of Nodes and Energy

Consumption at Server in case of DSR

Figure 8 shows Number of Nodes versus Energy Consumption at Server in the network in case of Dynamic Source Routing Protocol. In DSR protocol, Energy Consumption at Server in the Static categories is less as compared to the Semi-Dynamic categories and Dynamic categories. Similarly, Energy Consumption at Server in the Semi-Dynamic categories is less as compared to the Dynamic categories. Energy Consumption at Server occurs because of key distribution and key generation. In case of DSR protocol, it is a Reactive Routing Protocol and establishes routes only when required. Here, Energy Consumption is very less.

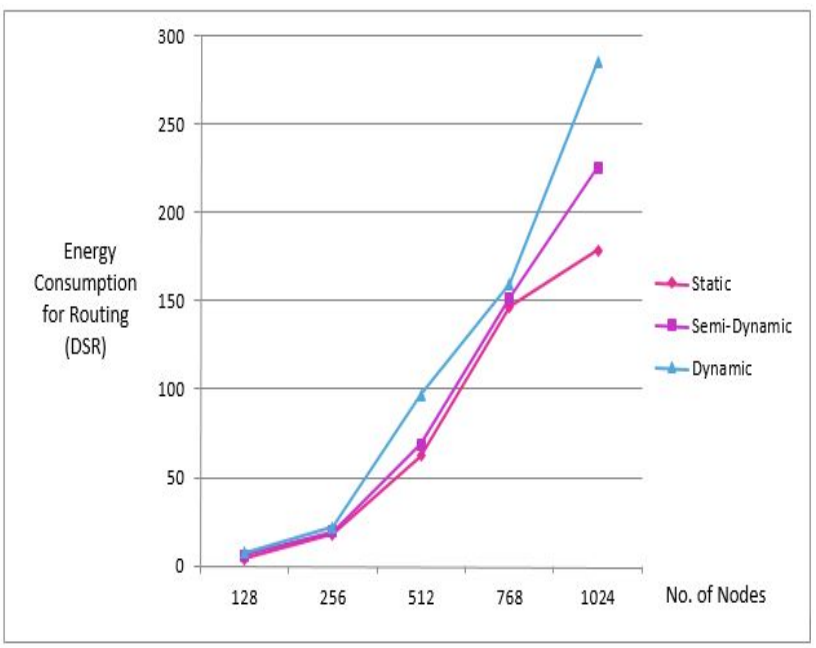

Figure 9: Graph between Number of Nodes and Energy Consumption for Routing in case of DSR

Figure 9 shows Number of Nodes versus Energy Consumption for Routing in the network in case of Dynamic Source Routing Protocol. In DSR protocol, Energy Consumption for Routing in the Static categories is less as compared to the Semi-Dynamic categories and Dynamic categories. Similarly, Energy Consumption for Routing in the Semi-Dynamic categories is less as compared to the Dynamic categories. Energy Consumption for Routing is smaller in case of DSR as compared to OLSR.

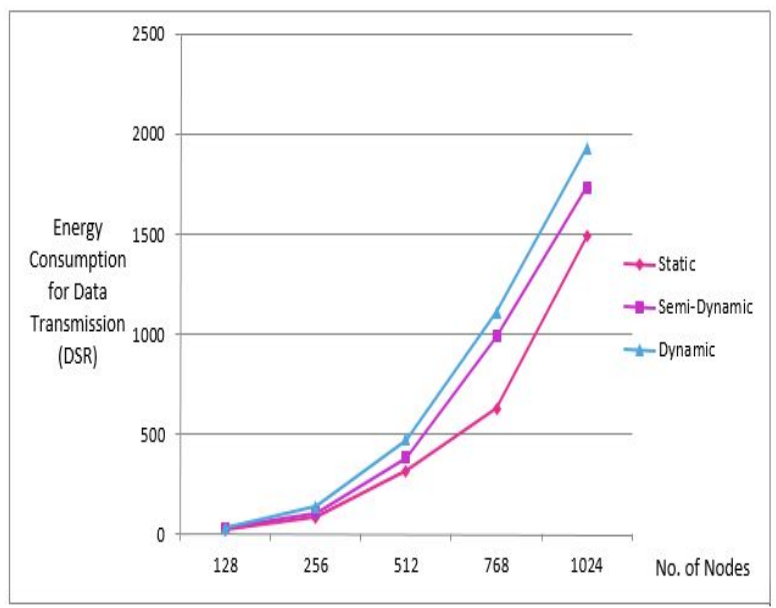

Figure 10: Graph between Number of Nodes and energy Consumption for Data Transmission in case of DSR

Figure 10 shows Number of Nodes versus Energy Consumption for Data Transmission in the network in case of Dynamic Source Routing Protocol. In DSR protocol, Energy Consumption for Data Transmission in the Static categories is less as compared to the Semi-Dynamic categories and Dynamic categories. Similarly, Energy Consumption for Data Transmission in the Semi-Dynamic categories is less as compared to the Dynamic categories. Energy Consumption for Data Transmission is smaller in case of DSR as compared to OLSR. 


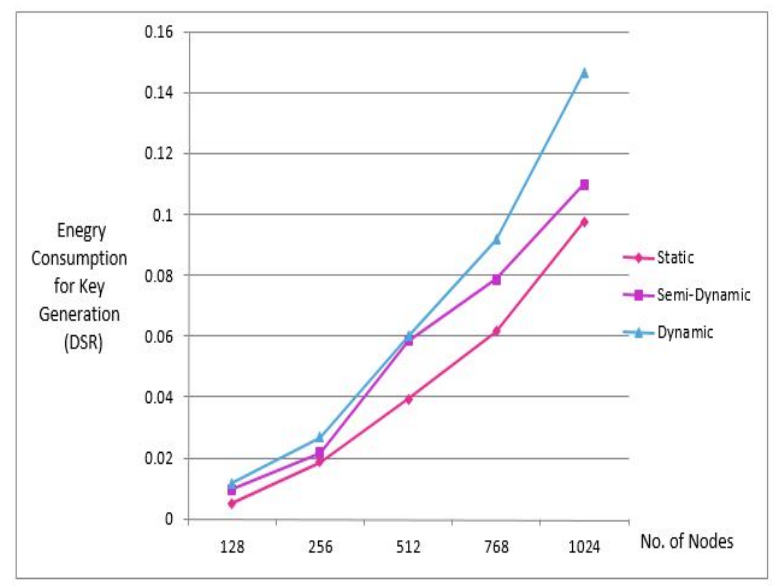

Figure 11: Graph between Number of Nodes and energy Consumption for Key Generation in case of DSR

Figure 11 shows Number of Nodes versus Energy Consumption for Key Generation in the network in case of Dynamic Source Routing Protocol. In DSR protocol, Energy Consumption for Key Generation in the Static categories is less as compared to the Semi-Dynamic categories and Dynamic categories. Similarly, Energy Consumption for Key Generation in the Semi-Dynamic categories is less as compared to the Dynamic categories. Here, it is observed that if number of Rekeys increase, the Energy Consumption for Key Generation also increases.

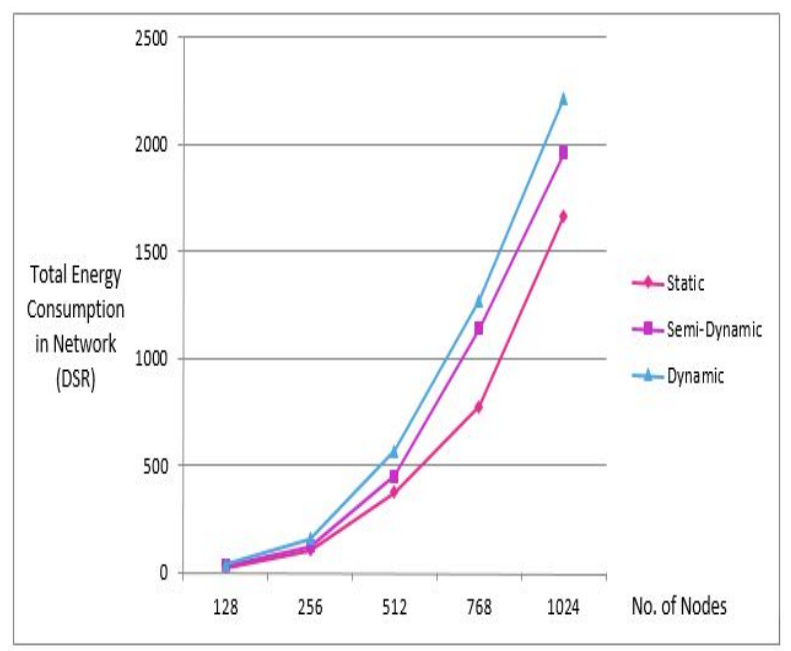

Figure 12: Graph between Number of Nodes and Total Energy Consumption in Network in case of DSR

Figure 12 shows Number of Nodes verses Total Energy Consumption in Network in case of Dynamic Source Routing Protocol. In DSR protocol, Total Energy Consumption in Network in the Static categories is less as compared to the Semi-Dynamic categories and Dynamic categories. Similarly, Total Energy Consumption in Network in the Semi-Dynamic categories is less as compared to the Dynamic categories. Total Energy Consumption in Network is the sum of Energy Consumption for Routing, Energy Consumption for Key Generation and Energy Consumption for Data Transmission.

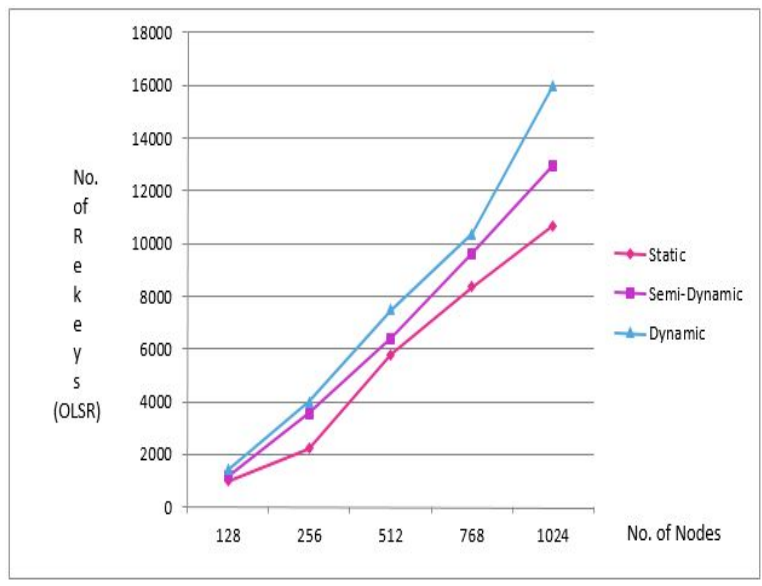

Figure 13: Graph between Number of Nodes and Number of Rekeys in case of OLSR

Figure 13 shows Number of Nodes versus Number of Rekeys in the network in case of Optimal Link State Routing Protocol.

In OLSR protocol, Rekey operation i.e. number of joining/leaving in the Static categories is less as compared to the Semi-Dynamic categories and Dynamic categories. Similarly, Rekey operation i.e. number of joining/leaving in the Semi-Dynamic categories is less as compared to the Dynamic categories.

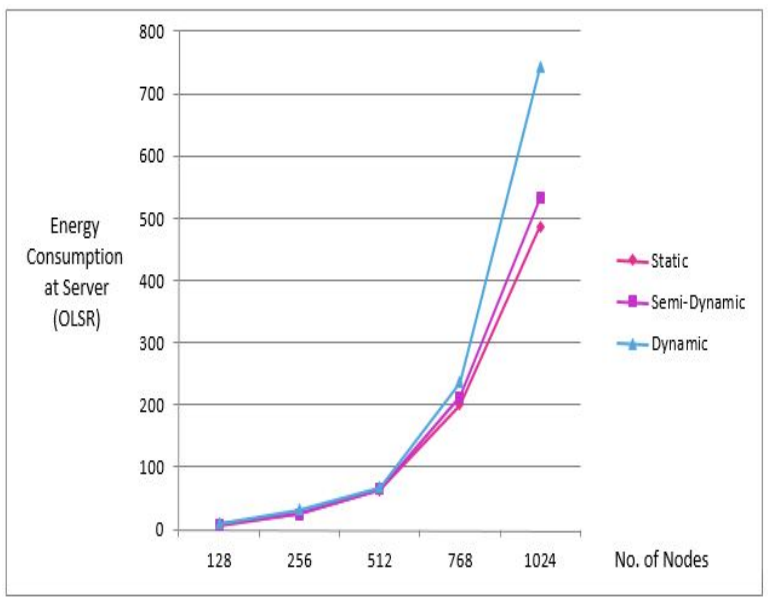

Figure 14: Graph between Number of Nodes and Energy Consumption at Server in case of OLSR

Figure 14 shows Number of Nodes versus Energy Consumption at Server in the network in case of Optimal Link State Routing Protocol.

In OLSR protocol, Energy Consumption at Server in the Static categories is less as compared to the Semi-Dynamic categories and Dynamic categories. Similarly, Energy Consumption at Server in the Semi-Dynamic categories is less as compared to the Dynamic categories.

Energy Consumption at Server occurs because of key distribution and key generation. In case of OLSR protocol, it is a Proactive Routing Protocol and computes routes to each node. It causes more energy depletion in the network. 


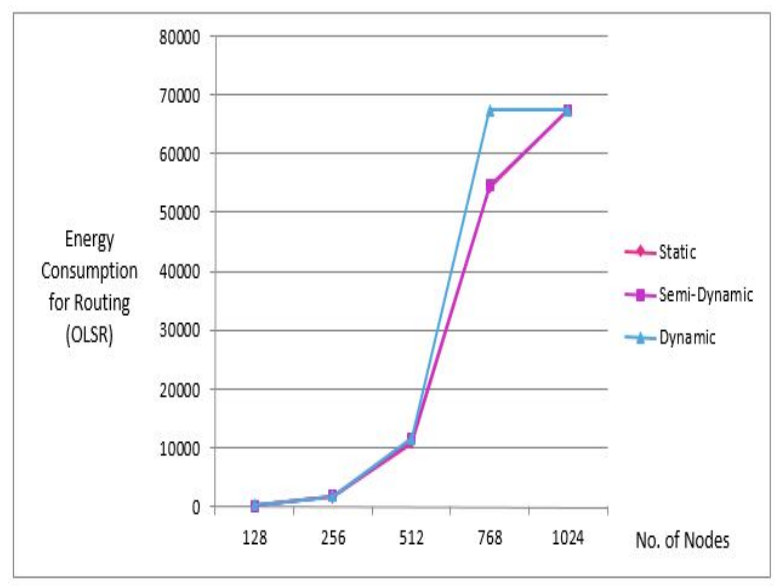

Figure 15: Graph between Number of Nodes and Energy Consumption for Routing in case of OLSR

Figure 15 shows Number of Nodes versus Energy Consumption for Routing in the network in case of Optimal Link State Routing Protocol. In OLSR protocol, Energy Consumption for Routing in the Static categories is less as compared to the Semi-Dynamic categories and Dynamic categories.

Similarly, Energy Consumption for Routing in the SemiDynamic categories is less as compared to the Dynamic categories. Energy Consumption for Routing is bigger in case of OLSR as compared to DSR.

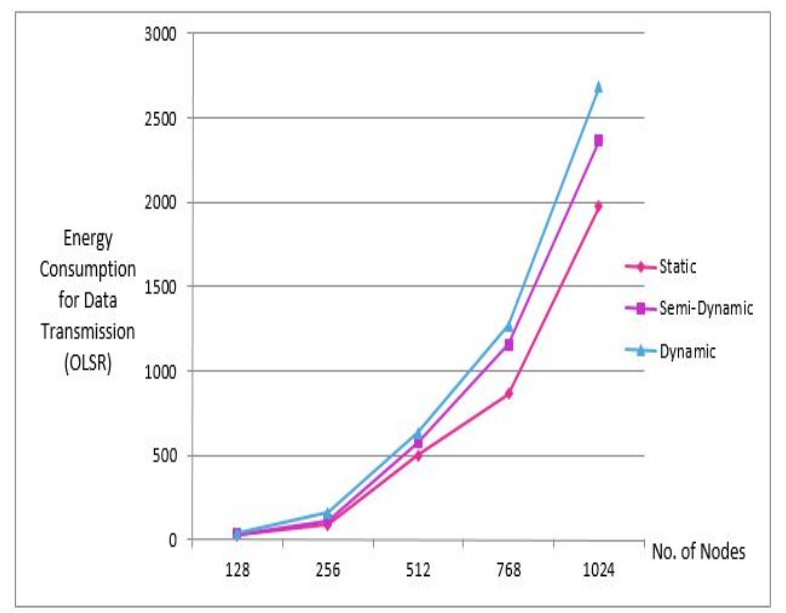

Figure 16: Graph between Number of Nodes and Energy Consumption for Data Transmission in case of OLSR

Figure 16 shows Number of Nodes versus Energy Consumption for Data Transmission in the network in case of Optimal Link State Routing Protocol. In OLSR protocol, Energy Consumption for Data Transmission in the Static categories is less as compared to the Semi-Dynamic categories and Dynamic categories.

Similarly, Energy Consumption for Data Transmission in the Semi-Dynamic categories is less as compared to the Dynamic categories.

Energy consumption for Data Transmission is bigger in case of OLSR as compared to DSR.

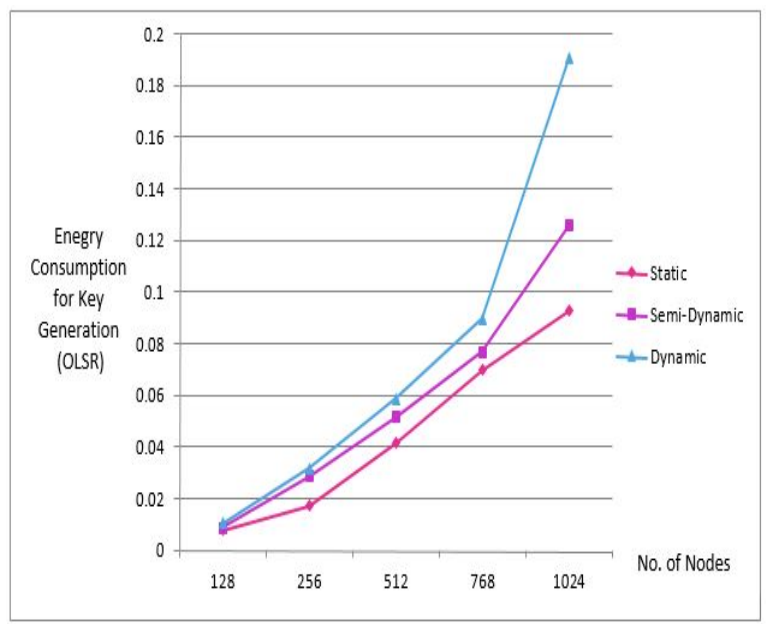

Figure 17: Graph between Number of Nodes and Energy Consumption for Key Generation in case of OLSR

Figure 17 shows Number of Nodes versus Energy Consumption for Key Generation in the network in case of Optimal Link State Routing Protocol. In OLSR protocol, Energy Consumption for Key Generation in the Static categories is less as compared to the Semi-Dynamic categories and Dynamic categories. Similarly, Energy Consumption for Key Generation in the Semi-Dynamic categories is less as compared to the Dynamic categories. Here, it is observed that if number of Rekeys increase, the Energy Consumption for Key Generation also increases.

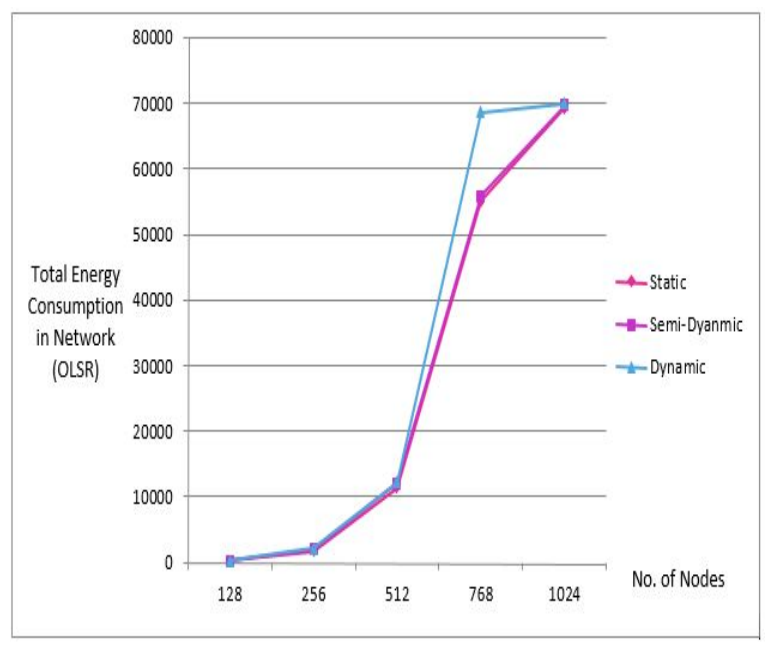

Figure 18: Graph between Number of Nodes and Total Energy Consumption in Network in case of OLSR

Figure 18 shows Number of Nodes versus Total Energy Consumption in Network in case of Optimal Link State Routing Protocol. In OLSR protocol, Total Energy Consumption in Network in the Static categories is less as compared to the Semi-Dynamic categories and Dynamic categories. Similarly, Total Energy Consumption in Network in the Semi-Dynamic categories is less as compared to the Dynamic categories. Total Energy Consumption in Network is sum of Energy Consumption for Routing, Energy Consumption for Key Generation and Energy Consumption for Data Transmission. 


\section{CONCLUSION}

Secure Group Communication is the most challenging issue in Mobile Ad-hoc Network. Reason behind this serious problem of centralization of administration, power consumptions and lack of fixed infrastructure. Power resources are limited for nodes in Mobile Ad-hoc Network. We have analyzed the logic of Optimal Probabilistic Logical Key Hierarchy which reduces Rekey Cost. Reduction of Rekey Cost reduces the cost of energy data transmission and consumption of energy which increases the longer existence of Mobile Ad-hoc Network.

\section{REFERENCES}

[1] X. Hong, K. Xu and M. Gerla, "Scalable routing protocols for mobile ad hoc networks”, IEEE network, Vol. 16, No. 4, Pp. 11-21, 2002.

[2] K. Huishan, C. Huimin and K.Y. Nam, "Routing Protocols in Ad-hoc Wireless Networks”, National University of Singapore, 2009.

[3] T. Lin, S.F. Midkiff and J.S. Park, "A framework for wireless ad hoc routing protocols", IEEE Wireless Communications and Networking, Vol. 2, Pp. 1162-1167, 2003.

[4] J. Macker, "Mobile ad hoc networking (MANET): Routing protocol performance issues and evaluation considerations", RFC 2501, IETF Network Working Group, 1999.

[5] T. Clausen and P. Jacquet, "Optimized Link State Routing Protocol (OLSR)”, RFC 3626, IETF Network Working Group, 2003.

[6] Y. Ge, T. Kunz and L. Lamont, "Quality of service routing in ad-hoc networks using OLSR", IEEE 36th Annual Hawaii International Conference on System Sciences, Pp. 1-9, 2003.

[7] P. Jacquet, P. Muhlethaler, T. Clausen, A. Laouiti, A. Qayyum and L. Viennot, "Optimized link state routing protocol for ad hoc networks", IEEE International Conference on Multi Topic, IEEE INMIC Technology for the 21st Century, Pp. 62-68, 2001.

[8] A. Laouti, P. Mühlethaler, A. Najid and E. Plakoo, "Simulation results of the olsr routing protocol for wireless network", Doctoral dissertation, INRIA, 2002.

[9] S.S. Kaushik and P.R. Deshmukh, "Comparison of effectiveness of AODV, DSDV and DSR Routing Protocols in Mobile Ad hoc Networks", International Journal of Information Technology and Knowledge Management, Vol. 2, No. 2, Pp. 499-502, 2009.

[10] http://www.digplanet.com/wiki/Random_waypoint_model.

[11] N.R. Potlapally, S. Ravi, A. Raghunathan and N.K. Jha, "Analyzing the energy consumption of security protocols", In Proceedings of the International Symposium on Low power electronics and design, Pp. 30-35, 2003.

[12] A.M. Hegland, E. Winjum, S.F. Mjolsnes, C. Rong, O. Kure and P. Spilling, "A survey of key management in ad hoc networks", IEEE Communications Surveys \& Tutorials, Vol. 8, No. 3, Pp. 48-66, 2006.

[13] J. Li, G. Cui, X. Fu, Z. Liu and L. Su, “A secure group key management scheme in ad hoc networks", IEEE International Conference on Wireless Communications, Networking and Mobile Computing, Vol. 2, Pp. 1156-1159, 2005.

[14] J. Biswas and S.K. Nandy, "Efficient Key Management and Distribution for MANET", IEEE International Conference on Communications, Vol. 5, Pp. 2256-2261, 2006.

[15] K. Gomathi and B. Parvathavarthini, "An efficient cluster based key management scheme for MANET with authentication”, IEEE Trendz in Information Sciences \& Computing (TISC), Pp. 202-205, 2010.

[16] M. Chatterjee, S.K. Das and D. Turgut, "An on-demand weighted clustering algorithm (WCA) for ad hoc networks", IEEE Conference on Global Telecommunications, Vol. 3, Pp. 1697-1701, 2000.

[17] A.R. Pais and S. Joshi, "A new probabilistic rekeying method for secure multicast groups”, International Journal of Information Security, Vol. 9, No. 4, Pp. 275-286, 2010.

[18] A.A. Selçuk and D. Sidhu, "Probabilistic optimization techniques for multicast key management”, Computer Networks, Vol. 40, No. 2, Pp. 219-234, 2002. 